ISSN 2587-8123 (Print) ISSN 2658-5995 (Online)

МИНИСТЕРСТВО НАУКИ И ВЫСШЕГО ОБРАЗОВАНИЯ РОССИЙСКОЙ ФЕДЕРАЦИИ ВОЛГОГРАДСКИЙ ГОСУДАРСТВЕННЫЙ УНИВЕРСИТЕТ

НИЖНЕВОЛЖСКИЙ АРХЕОЛОГИЧЕСКИЙ ВЕСТНИК 2021 Tом 20. № 2

MINISTRY OF SCIENCE AND HIGHER EDUCATION OF THE RUSSIAN FEDERATION VOLGOGRAD STATE UNIVERSITY

THE LOWER VOLGA ARCHAEOLOGICAL BULLETIN 2021 Volume 20. No. 2

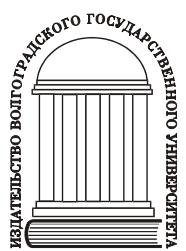




\section{СОДЕРЖАНИЕ}

Конец прекрасной эпохи (Редакциионная коллегия) .... 5

\section{СТАТЬИ}

Файзуллин И.А., Купцова Л.В., Мухаметдинов В.И. Гончарное производство срубной культуры Предуралья по материалам курганного могильника I у села Твердилово

Балабанова М.А., Клепиков В.М., Перерва Е.В. Погребальный обряд и морфология погребенного из кургана могильника Тау (Западный Казахстан) .... 24

Монахов С.Ю. Типология и хронология аканфских амфор [На англ. яз.] 43

Абрамова А.Н. Население Прикубанья раннего железного века по данным краниофенетики (предварительные данные) .66

Малашев В.Ю., Маслов В.Е. Курганы-кладбища центральных и восточных районов Северного Кавказа III в. до н.э. - начала (первой половины) II в. н.э. (памятники типа Чегем-Манаскент)

Ковалева К.С. Производственные

бронзолитейные комплексы

городов Золотой Орды: поиск аналогий

Дрёмов И.И., Круглов Е.В. Железные конусы в погребениях Улуса Джучи:

аспекты этнокультурной принадлежности 149

Гаглойты Р.Х., Кочкаров У.Ю., Мамаев Р.Х., Нарожный В.Е., Нарожный Е.И. Наконечники копий келийского каменноящечного могильника (Горная Ингушетия)

\section{ПУБЛИКАЦИИ}

Кривочеев М.В., Моисеев В.И.

Погребения раннесарматского времени

с территории Чеченской Республики

Иванов С.С. Редкая поясная бляха

в зооморфном стиле с Внутреннего Тянь-Шаня..... 196

Николаев С.Ю. Три сарматских кинжала

с подножия горы Торатау 204

\section{НАУЧНАЯ ЖИЗНЬ}

Итоги VI Нижневолжской Международной археологической научной конференции «Волго-Уральский регион от древности до Средневековья» (Оргкомитет конферениии) 214

\section{CONTENTS}

The End of a Great Era (Editorial Staff) 5

\section{ARTICLES}

Fayzullin I.A., Kuptsova L.V., Mukhametdinov V.I. The Ceramics Production of the Cis-Ural Srubnaya Culture: A Case Study of the Kurgan Cemetery I Near Tverdilovo Village ..... 8

Balabanova M.A., Klepikov V.M., Pererva E.V. Funeral Rite and Morphology of a Buried Man from Kurgan of Tau Cemetery (Western Kazakhstan) .... 24 Monakhov S.Yu. Typology and Chronology of Akanthian Amphorae

Abramova A.N. Craniophenetic Features

of Cis-Kuban Population of the Early Iron Age (Preliminary Data)

Malashev V.Yu., Maslov V.E. Kurgan-Cemeteries of Central and Eastern Regions of North Caucasus $3^{\text {rd }}$ Century BC - Early $2^{\text {nd }}$ Century AD

(Monuments Chegem-Manaskent Type)

Kovaleva K.S. Manufacturing Complexes for the Non-Ferrous Metals Processing of the Golden Horde Cities: Search for Analogies

Dremov I.I., Kruglov E.V. Iron Cones

in the Burials of Ulus Jochi:

Aspects of Ethnocultural Identification

Gagloiti R.H., Kochkarov U.U., Mamaev R.Kh., Narozhnyi V.E., Narozhnyi E.I. Spearheads of the Keliysky Stone Box Burial Ground (Ingushetia Highlands)

\section{PUBLICATIONS}

Krivosheev M.V., Moiseev V.I.

Early Sarmatian Burials

from the Chechen Republic Territory

Ivanov S.S. A Rare Belt Plaque in Zoomorphic Style from the Inner Tien Shan.... 196

Nikolaev S.Yu. Three Sarmatian Daggers

from the Foot of Toratau Mount

\section{SCIENTIFIC LIFE}

Proceedings of the $6^{\text {th }}$ Lower Volga International Scientific Conference on Archaeology

"The Volga-Ural Region -

from Antiquity to the Middle Ages"

(Organizing Committee of the Conference) 214 


\title{
THREE SARMATIAN DAGGERS FROM THE FOOT OF TORATAU MOUNT
}

\author{
Sergey Yu. Nikolaev \\ Ufa Federal Research Center of the Russian Academy of Sciences, Ufa, Russian Federation
}

\begin{abstract}
Three Sarmatian daggers found during plowing a field at the foot of Toratau Mount in the Southern Urals are published. Their detailed description is given. It is stated that two daggers bear the signs of the early Sarmatian type of bladed weapons. They date back to the $3^{\text {rd }}-2^{\text {nd }}$ centuries BC, their discovery confirms the fact of active resettlement by the Sarmatians of the right bank of the Belaya River at this time. The third dagger bears a number of archaic features, has close analogies among random finds in the Prokhorov cemetery and on the left bank of the Belaya River. It dates back to the $4^{\text {th }}-3^{\text {rd }}$ centuries BC. It is noted that the left bank of the Belaya River is the main territory of settlement of early nomads in the Southern Urals. The description of the topography of the daggers found in the site is given. It is shown that according to its physical and geographical characteristics, this territory is a closed valley, bounded on all sides by the river, the Turatau and Kushtau Mountains, and gentle ridges running along the Belaya River. It is concluded that in this case, the "valley" version of the settlement of early nomads was implemented, as well as that the settlement of the right bank of the Belaya River occurred, apparently, from its left bank. This territory was a natural periphery of the settlement of nomads in the Southern Urals in the second half-end of the 1st millennium BC.
\end{abstract}

Key words: Southern Urals, right bank of the Belaya River, Toratau Mountain, early nomads, ScythianSarmatian time, Prokhorov culture, stray finds, daggers, resettlement system.

Citation. Nikolaev S.Yu., 2021. Tri sarmatskih kinzhala s podnozhiya gory Toratau [Three Sarmatian Daggers from the Foot of Toratau Mount]. Nizhnevolzhskiy Arkheologicheskiy Vestnik [The Lower Volga Archaeological Bulletin], vol. 20, no. 2, pp. 204-213. DOI: https://doi.org/10.15688/nav.jvolsu.2021.2.11

УДК 903.2(470.57):397

Дата поступления статьи: 06.07.2021

ББК 63.4(2Рос.Баш)

Дата принятия статьи: 30.10 .2021

\section{ТРИ САРМАТСКИХ КИНЖАЛА С ПОДНОЖИЯ ГОРЫ ТОРАТАУ}

\section{Сергей Юрьевич Николаев}

Уфимский федеральный исследовательский центр РАН, г. Уфа, Российская Федерация

Аннотация. Публикуются три сарматских кинжала, найденные при распашке поля у подножия горы Торатау в Южном Приуралье. Дается их подробное описание. Констатируется, что два кинжала несут признаки сложившегося раннесарматского типа клинкового оружия. Они датируются III-I вв. до н.э., их находка подтверждает факт активного заселения сарматами правобережья реки Белой в это время. Третий кинжал несет в себе ряд архаичных черт, имеет близкие аналогии в Прохоровском могильнике и среди случайных находок на левом берегу р. Белой. Он датируется IV-III вв. до н.э. Отмечается, что основной территорией расселения ранних кочевников в Южном Приуралье является левобережье р. Белой. Дается описание топографии места находки кинжалов. Показано, что по своим физико-географическим характеристикам эта территория представляет собой замкнутую долину, ограниченную со всех сторон рекой, горами Торатау и Куштау и пологими хребтами, идущими вдоль реки Белой. Делается вывод о том, что в данном случае был реализован «долинный» вариант расселения ранних кочевников, а также о том, что заселение правобережья реки Белой происходило, по всей видимости, с ее левого берега. Данная территория была естественной периферией расселения кочевников на Южном Приуралье во второй половине - конце I тыс. до н.э.

Ключевые слова: Южный Урал, правобережье реки Белой, гора Торатау, ранние кочевники, скифосарматское время, прохоровская культура, случайные находки, кинжалы, система расселения. 
Цитирование. Николаев С. Ю., 2021. Три сарматских кинжала с подножия горы Торатау // Нижневолжский археологический вестник. Т. 20, № 2. С. 204-213. DOI: https://doi.org/10.15688/nav.jvolsu.2021.2.11

Основной территорией, на которой в Южном Приуралье происходило расселение кочевников скифо-сарматского времени, являлось левобережье реки Белой. Именно там известны как погребальные комплексы (Старые Киишки, Бишунгарово, Леканды и др.), так и массовые, так называемые случайные находки мечей и кинжалов, связанные именно с кочевавшими здесь группами номадов [Археологическая карта Башкирии, 1976, с. 140-161; Исмагилов, 2001; Савельев, Николаев, 2020; Николаев, 2019; 2021a; 2021б; и др.].

На правом берегу реки Белой, в достаточно узкой (не более 25 км) полосе между рекой и Уральскими горами, в настоящее время известно лишь одно погребение, относящееся к ранним кочевникам - впущенное в насыпь кургана 3 Береговского могильника в Мелеузовском районе Башкирии [Горбунов, Иванов, 1992, с. 105]. Какие-либо иные погребальные или поселенческие сарматские памятники на этой территории неизвестны. Зато зафиксировано около десятка опубликованных на настоящий момент случайных находок мечей и кинжалов как савроматского, так и сарматского типа. Иная картина наблюдается на противоположном, левом берегу реки, где известны как многочисленные могильники, так и находки мечей и кинжалов.

В настоящей статье публикуются данные по трем кинжалам, найденным в 1980-е годы на правом берегу реки Белой, на пашне у подножья шихана Торатау возле руин лагеря системы ГУЛАГ, местными жителями при проведении полевых работ. Место находки расположено в 2 км к северу от села Урман-Бишкадак Ишимбайского района Башкирии и в 8 км к юго-востоку от г. Стерлитамак. Они были переданы в школьный музей села Урман-Бишкадак, где хранятся и поныне. В 2019 г. экспедицией ИИЯЛ УФИЦ РАН в ходе обследования территории проектируемого геопарка «Торатау» эти кинжалы были сфотографированы, зарисованы и описаны.

Кинжал 1. Общая длина кинжала 35 см, кончик клинка отсутствует (рис. 2,1). Навершие не сохранилось, от него осталась только небольшая (диаметром не более 0,8 см и тол- щиной 1-2 мм) площадка (место сварки?). Рукоять в сечении ромбическая, ее длина 6,2 см, ширина 0,6-1 см, плавно расширяющаяся к перекрестью. В 1 см от места крепления навершия ребро ромба расковано. Перекрестье прямое, его длина 6,8 см, ширина 0,6 см. Оно сдвинуто со своего первоначального места и расположено на 0,7 см ниже места перехода рукояти в клинок. Клинок вытянуто-треугольной формы, ромбовидный в сечении. Сохранившаяся длина клинка 27,7 cм (первоначально - не более 30-31 см), ширина возле перекрестья 3,9 см, возле обломанного кончика $1 \mathrm{~cm}$, максимальная толщина 0,6 см.

В целом все основные элементы кинжала (без учета отсутствующего навершия) соответствуют классическому прохоровскому типу, наиболее частому среди так называемых случайных находок в Южном Приуралье [Мошкова, 1963, с. 33-35, табл. 18, 19; 1974, c. 11-14, рис. $1,52-55,2,69-71$; Горбунов, Исмагилов, 1976, с. 234-235; Исмагилов, 2001, табл. IV-IX; Савельев, Николаев, 2020 , рис. $1,1,2 ;$ Николаев, 2019, рис. $2 ; 20216$, рис. 2 , $3,1,2,4,5,1,4]$.

Кинжал 2. Общая длина кинжала 39 см (рис. 2,2). Навершие кольцевидное (или разомкнутое кольцевидное), частично обломано, длина сохранившейся части $4 \mathrm{~cm}$, в сечении овальное, диаметр дрота 0,5 см. Рукоять прямоугольная в сечении, длиной $8 \mathrm{~cm}$, шириной 1,3 см, толщиной 0,6 см. Перекрестье брусковидное, слегка изогнуто в сторону клинка, его длина 5,5 см, ширина 0,4 см. Клинок вытянуто-треугольной формы, ромбовидный в сечении. Его длина 30,6 cм, толщина в месте сечения 0,7 см. От перекрестья с обеих сторон клинка на длину 13,5 см идут по два дола шириной 4 мм, треугольные в сечении.

Очевидно, что кинжал несет в себе признаки двух типов клинкового оружия - форма перекрестья и клинка, а также его сечение соответствуют сложившемуся прохоровскому типу, в то время как рукоять и навершие более характерны для среднесарматского типа. Ранее уже отмечалось большое количество мечей и кинжалов, сочетающих в себе признаки обоих типов, как среди «случайных» 
находок Южного Приуралья, так и в погребальных комплексах [Савельев, Николаев, 2020; Николаев, 2021 а; 2021б].

Кинжалы 1 и 2 имеют аналоги в Бишунгаровских курганах [Пшеничнюк, 1983, табл. X, $8, \mathrm{XI}, 7, \mathrm{XXII,} 8, \mathrm{XXIII,14,15]} \mathrm{и} \mathrm{в} \mathrm{курга-}$ нах у д. Старые Киишки [Садыкова, 1962a, табл. III,11,13, IX,8, XII,3; Садыкова, 1962б, рис. 2,12$]$. Оба могильника датируются IIIII вв. до н.э. [Пшеничнюк, 1983, с. 77; Садыкова, Васильев, 2001, с. 65-68; Федоров 2011, c. 37; Скрипкин, 2017, с. 65-86]. Позднее-во второй половине II - I в. до н.э. - носители прохоровской культуры практически покидают Южное Приуралье севернее возвышенностей Общего Сырта. Известны только единичные могильники с очень бедным инвентарем (Ново-Калкашевский [Акбулатов, 1998], Набережный могильники). Каких-либо исследований по типологии, позволяющих выделить ранние и поздние признаки из всего массива прохоровских мечей и кинжалов, что вывело бы на построение эволюционной схемы развития прохоровского клинкового оружия, в настоящее время также не проводилось. В связи с этим оба публикуемых кинжала по тенденции могут быть датированы III-ІІ вв. до н.э., однако не исключено их существование в Южном Приуралье и в I в. до н.э., вплоть до рубежа эр и даже несколько позже.

Кинжал 3. Общая длина кинжала 33 см, сохранился полностью (рис. 3,1). Навершие прямое, общая длина 7,3 см, в сечении округлое, диаметр дрота возле рукояти $1 \mathrm{~cm}$, сужается к кончикам антенн до $0,5-0,6$ см. Рукоять длиной 8 см, шириной $1,8-2$ см, двутавровая в сечении. Ее толщина 0,7 см, глубина желобка составляет 3 мм. Перекрестье прямое, брусковидное, длиной 5,1 см, очень широкое $(1,3 \mathrm{~cm})$ и очень тонкое $(0,5 \mathrm{~cm})$. Длина клинка $22,5 \mathrm{~cm}$, сечение линзовидное, до середины лезвия параллельны, далее форма клинка вытянуто-треугольная. Ширина клинка возле перекрестья 3,5 см, максимальная толщина 0,3 см.

Все элементы кинжала несут в себе достаточно ранние признаки: прямое, массивное навершие и не менее массивное перекрестье, двутавровая рукоять и линзовидный в сечении клинок с параллельными до середины лезвиями. Полная аналогия такому кинжалу об- наруживается в погребении 2 кургана 2 Прохоровского могильника, расположенного в 100 км к юго-западу от Торатау (рис. 3,2). Л.Т. Яблонский датировал его IV-III вв. до н.э. [Яблонский, 2010, с. 76, рис. 50,30]. Схожий кинжал известен также и среди случайных находок в пос. Сосновка, на левом берегу р. Белой, в 33 км к северу - северо-западу от Торатау [Исмагилов, 2001, с. 121, табл. III,22]. Несмотря на отличия в сечении клинка, в остальном данный экземпляр несет те же архаичные признаки, что и кинжал из Урман-Бишкадака (рис. 3,3 ). Подробный анализ кинжалов с архаичными чертами, в том числе с двутавровой рукоятью, дал В.К. Федоров, проанализировав выборку из двух десятков образцов клинкового оружия, справедливо определив их как финальный этап при смене оружия переходного типа классическим прохоровским и датировав концом IV - III в. до н.э. [Федоров, 2008, с. 74-76].

Место находки кинжалов расположено примерно в 300-400 м к западу - юго-западу от склона горы Торатау, на второй надпойменной террасе правого берега реки Белой (рис. 1). Сама река протекает на 2 км западнее. Долина реки на данном участке с востока ограничена идущим вдоль реки залесенным хребтом высотой около 140 м. В 13 км к северу от места находки кинжалов, возле ныне не существующего шихана Шахтау, долина пересекается впадающим в р. Белую ее правым притоком р. Селеук. Далее долина продолжается вдоль другого хребта высотой до 150 м и через 3 км упирается в расположенный непосредственно возле реки шихан Куштау, где также известна находка кинжала прохоровского времени с разомкнутым кольцевидным навершием [Исмагилов, 2001, с. 125, табл. Х,96]. Таким образом, гора, хребет и река образуют практически замкнутую долину.

Общие размеры рассматриваемого участка долины р. Белой составляют $20 \times 8$ км (в самом широком ее месте). Широкая (до 4,5-5 км) пойма образует заливные луга. Долина пересечена большим количеством небольших рек и ручьев, впадающих в р. Белую.

Ранее уже отмечались два варианта расселения ранних кочевников Южного Приуралья, зависящие от рельефа местности. 
В первом случае кочевники селились в долине относительно крупной реки, ограниченной с внешней стороны возвышенностями, которые являются естественными границами «волостей» [Савельев, 2016; 2018]. Во втором - центром «волости», или «соты», являлась водораздельная возвышенность, а естественными границами становились окружающие ее реки. Второй вариант расселения более свойственен относительно ровному рельефу обживаемой территории и хорошо выделяется на левобережье р. Белой [Николаев, 2019; Савельев, Николаев, 2020]. В рассматриваемом случае налицо именно первый, «долинный» вариант. Два хребта и река Белая образовали естественные границы освоенной территории.

Находка первых двух кинжалов (№ 1 и № 2), с классическими прохоровскими признаками, дополнительно подтверждает факт того, что правобережье реки Белой в его степной части плотно осваивалось ранними кочевниками в III-II вв. до н.э.

Исходя из физико-географических данных, освоение сарматами правобережья р. Белой могло идти двумя путями. Они могли прийти туда с юга, из долины р. Большой Ик, и далее на север вдоль западных склонов Уральских гор. Второй вариант заселения - с запада, с левобережья реки Белой, освоенного ранними кочевниками еще с савроматского времени [Савельев, 2016, с. 244].

Находка третьего кинжала, с архаичными чертами, имеющего прямую аналогию в Прохоровском могильнике и на левом берегу р. Белой, говорит о том, что заселение сарматами правого берега, скорее всего, проходило именного с ее левобережья. Таким образом, предгорное правобережье реки Белой являлось на данной широте естественной периферией расселения кочевников во второй половине - конце I тыс. до н.э. 


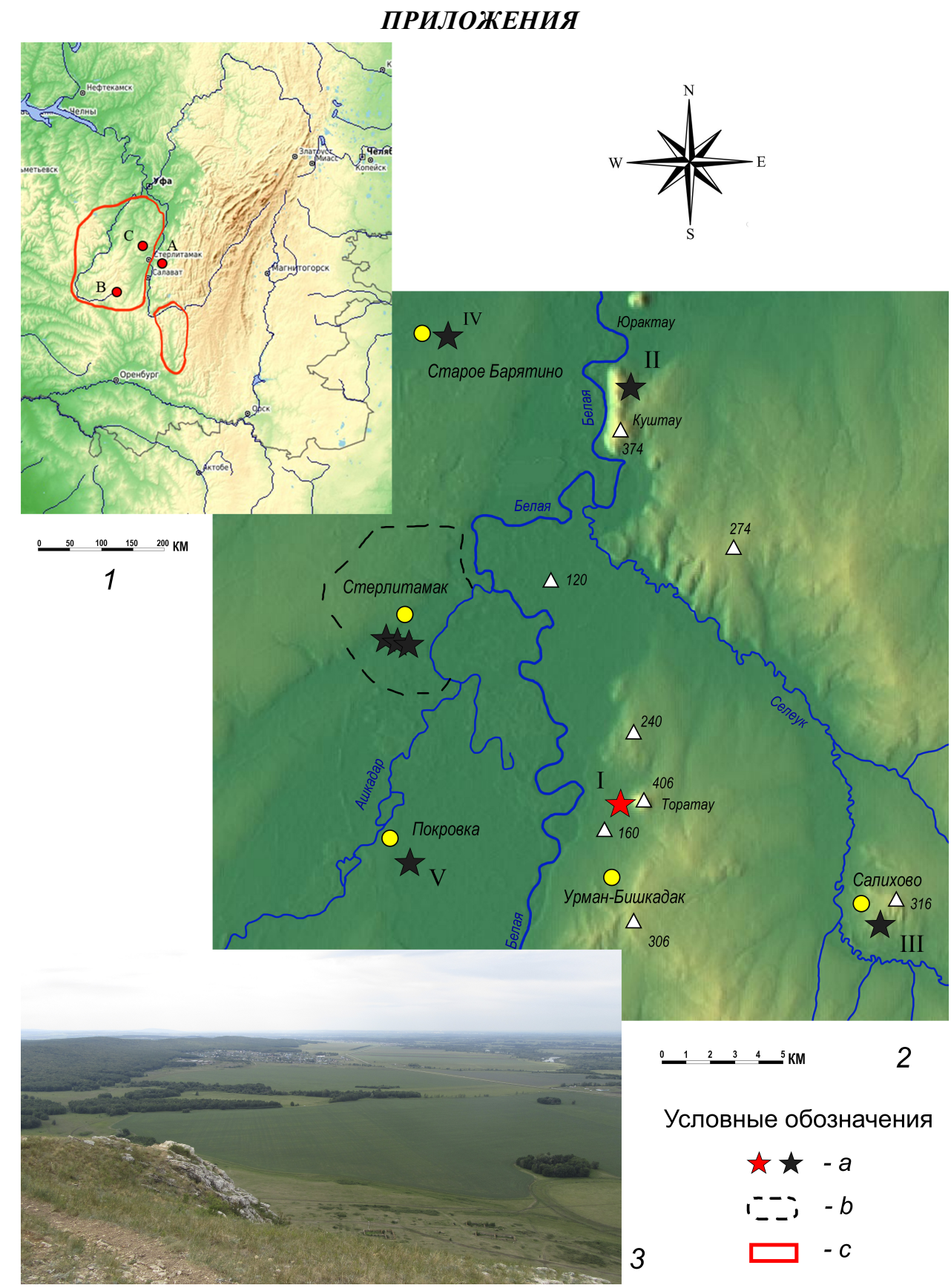

Рис. 1. Находки кочевнического клинкового оружия:

1 - общая карта Южного Урала (А - гора Торатау; В - Прохоровские курганы; С - пос. Сосновка); 2 - ландшафтная карта долины р. Белая на широте горы Торатау (I - находки кинжалов около г. Торатау; $\mathrm{I}-\mathrm{V}$ - прочие случайные находки мечей и кинжалов); 3 - вид на место находки кинжалов, долину р. Белая и хребет вдоль нее с вершины г. Торатау.

Условные обозначения: $a$ - места случайных находок мечей и кинжалов; $b$ - границы современной городской застройки; $c$ - ареал распространения случайных находок мечей и кинжалов в Южном Приуралье (по: [Савельев, 2016, с. 242, рис. 1] с дополнениями автора)

Fig. 1. Finds of nomadic bladed weapons:

1 - general map of the Southern Urals (A - Toratau mountain; B - Prokhorovka kurgans; C - Sosnovka village);

2 - landscape map of the Belaya River valley at the latitude of Mount Toratau (I - finds of daggers near Toratau; $\mathrm{I}-\mathrm{V}$ - other accidental finds of swords and daggers); 3 - view of the site of the discovery of daggers, the valley of the Belaya River and the ridge along it from the top of Toratau.

Symbols: $a$ - places of accidental finds of swords and daggers; $b$ - the boundaries of modern urban development; $c-$ the area of distribution of accidental finds of swords and daggers in the Southern Urals (after: [Savelev, 2016, p. 242, fig. 1] with additions by the author) 

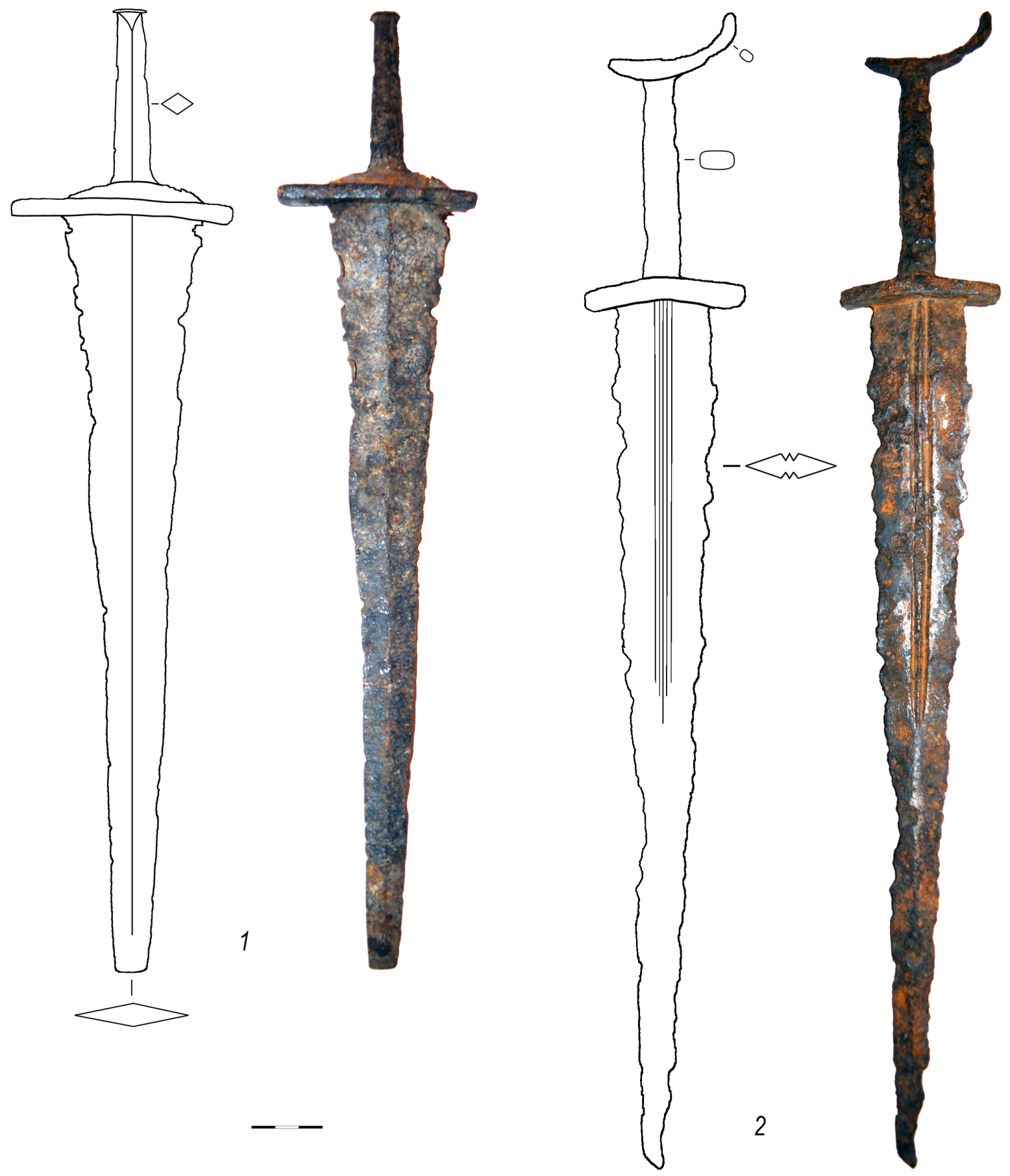

Рис. 2. Гора Торатау. Находки кочевнического клинкового оружия:

1 - кинжал 1; 2 - кинжал 2 (фото М.М. Румянцева, рисунок и компьютерная обработка автора)

Fig. 2. Mount Toratau. Finds of nomadic bladed weapons:

1 - dagger 1;2 - dagger 2 (photo by M.M. Rumyantsev, drawing and computer processing by author) 

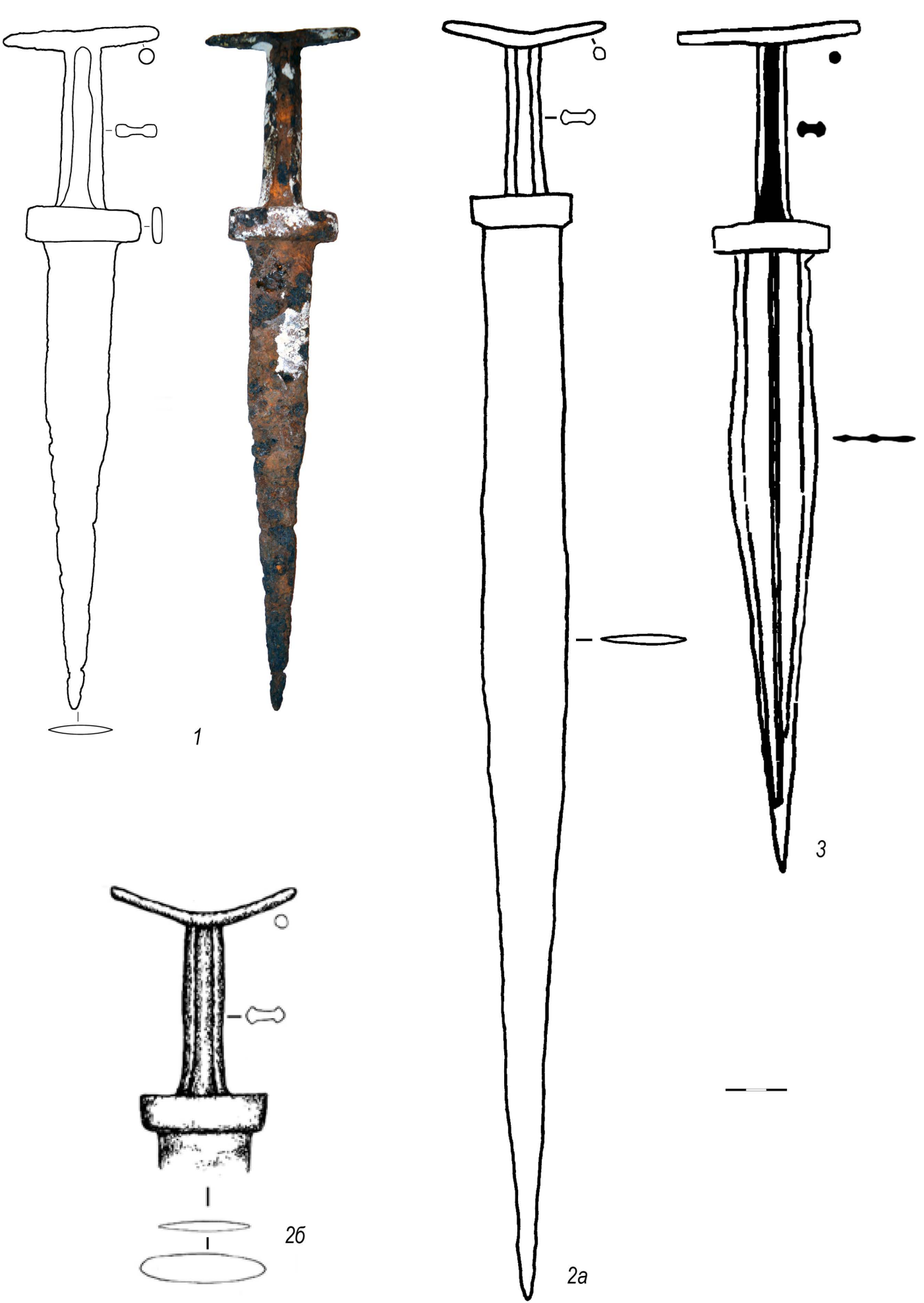

Рис. 3. Гора Торатау. Находки кочевнического клинкового оружия:

1 - кинжал 3 (фото М.М. Румянцева, рисунок и компьютерная обработка автора);

2 - кинжал из погребения 2 кургана 2 Прохоровского могильника $(2 a-$ рисунок автора,

26 - по: [Яблонский, 2010, с. 76, рис. 50,30]); 3 - кинжал из пос. Сосновка (по: [Исмагилов, 2001, с. 121, табл. III,22])

Fig. 3. Mount Toratau. Finds of nomadic bladed weapons:

1 - dagger 3 (photo by M.M. Rumyantsev, drawing and computer processing by the author);

2 - a dagger from the burial of 2 barrows 2 of the Prokhorovsky kurgan cemetery $(2 a$ - drawing by the author, 26 - after: [Yablonskiy, 2010, p. 76, fig. 50,30]); 3-dagger from the village Sosnovka (after: [Ismagilov, 2001, p. 121, table III,22]) 


\section{СПИСОК ЛИТЕРАТУРЫ}

Акбулатов И. М., 1998. Ново-Калкашский II курганный могильник на р. Стерля // Уфимский археологический вестник. Вып. 1. С. 121-137.

Археологическая карта Башкирии, 1976. М. : Наука. 264 с.

Горбунов В. С., Исмагилов Р. Б., 1976. Новые находки мечей и кинжалов савромато-сарматского времени в Башкирии // Советская археология. № 3. С. 229-247.

Горбунов В. С., Иванов В. А., 1992. Новые памятники ранних кочевников в Южном Приуралье // Проблемы хронологии сарматской культуры. Саратов : Изд-во Сарат. гос. ун-та. С. 99-109.

Исмагилов Р. Б., 2001. Клинковое оружие эпохи ранних кочевников из Южного Приуралья (случайные находки) // Уфимский археологический вестник. Вып. 3. С. 117-147.

Мошкова М. Г., 1963. Памятники прохоровской культуры. САИ. Вып. Д1-10. М. : Изд-во Акад. наук СССР. 56 с., 32 табл.

Мошкова М. Г., 1974. Происхождение раннесарматской (прохоровской) культуры. М. : Наука. 51 с.

Николаев С. Ю., 2019. Комплекс сарматского клинкового оружия из окрестностей сел Куезбашево и Бишкаин в Южном Приуралье // У фимский археологический вестник. Вып. 19. С. 69-77. DOI: https://doi.org/ 10.31833/uav.2019.19.006.

Николаев С. Ю., 2021а. Мечи и кинжалы с кольцевидным навершием: случайные находки с территории Южного Приуралья // Археология евразийских степей. № 2. С. 170-174. DOI: https://doi.org/10.24852/25876112.2021.2.170.174.

Николаев С.Ю., 2021б. Случайные находки мечей и кинжалов ранних кочевников северо-восточной периферии степей Южного Приуралья (вторая половина I тыс. до н.э. - рубеж эр) // Уфимский археологический вестник. 2021. Т. 21, № 1. C. 128-144. DOI: https://doi.org/10.31833/uav/2021.21.1.012.

Пшеничнюк А. Х., 1983. Культура ранних кочевников Южного Урала. М. : Наука. 199 с.

Савельев Н. С., 2016. Мечи и кинжалы в культовой практике кочевников Южного Приуралья скифо-сарматского времени (пространственный анализ «случайных» находок) // Константин Федорович Смирнов и современные проблемы сарматской археологии : материалы IX Междунар. науч. конф. «Проблемы сарматской археологии и истории». Оренбург : Изд-во ОГПУ. С. 241-253.

Савельев Н. С., 2018. Находки мечей и кинжалов скифо-сарматского времени из юго-западных предгорий Южного Урала (к вопросу об освоении территории и особенностях расселения кочевников) // Oriental Studies. T. 11, № 4. C. 24-31.

Савельев Н. С., Николаев С. Ю., 2020. Комплекс сарматских кинжалов из окрестностей с. Толбазы в Южном Приуралье // Нижневолжский археологический вестник. Т. 19, № 1. С. 149-166. DOI: https://doi.org/ 10.15688/nav.jvolsu.2020.1.8.

Садыкова М. Х., 1962а. Сарматский курганный могильник у дер. Старые Киишки // Археология и этнография Башкирии. Т. 1. Уфа : Башкир. фил. Акад. наук СССР. С. 88-122.

Садыкова М. Х., 1962б. Сарматские памятники Башкирии // Материалы и исследования по археологии СССР. Вып. 115. М. : Изд-во Акад. наук СССР. С. 242-273.

Садыкова М. Х., Васильев В. Н., 2001. Поздние прохоровцы в Центральной Башкирии // Уфимский археологический вестник. Вып. 3. С. 55-80.

Скрипкин А. С., 2017. Сарматы. Волгоград : Изд-во ВолГУ. 293 с.

Федоров В. К., 2008. О датировке 1-4 Прохоровских курганов // Уфимский археологический вестник. Вып. 8. C. $69-90$.

Федоров В. К., 2011. Курган 12 могильника Старые Киишки // Уфимский археологический вестник. Вып. 11. С. $28-38$.

Яблонский Л. Т., 2010. Прохоровка. У истоков сарматской археологии. М. : Таус. 384 с.

\section{REFERENCES}

Akbulatov I.M., 1998. Novo-Kalkashskij II kurgannyj mogil'nik na r. Sterlya [Novo-Kalkashsky II burial mound on the Sterlya River]. Ufimskiy arkheologicheskiy vestnik [The Ufa Archaeological Herald], iss. 1, pp. 121-137. 
Arkheologicheskaya karta Bashkirii [Archaeological Map of Bashkiria], 1976. Moscow, Nauka Publ. 264 p.

Gorbunov V.S., Ismagilov R.B., 1976. Novye nahodki mechey i kinzhalov savromato-sarmatskogo vremeni v Bashkirii [New Finds of Swords and Daggers of the Sauromatian-Sarmatian Time in Bashkiria]. Sovetskaya arkheologiya [Soviet Archaeology], no. 3, pp. 229-247.

Gorbunov V.S., Ivanov V.A., 1992. Novye pamyatniki rannih kochevnikov v Yuzhnom Priural'e [New Monuments of Early Nomads in the Southern Urals]. Problemy hronologii sarmatskoy kul tury [Problems of Chronology of the Sarmatian Culture]. Saratov, SSU, pp. 99-109.

Ismagilov R.B., 2001. Klinkovoe oruzhie epohi rannih kochevnikov iz Yuzhnogo Priural'ya (sluchaynye nahodki) [Bladed Weapons of the Early Nomadic Period from the Southern Cis-Urals (Accidental Findings)]. Ufimskiy arkheologicheskiy vestnik [The Ufa Archaeological Herald], iss. 3, pp. 117-147.

Moshkova M.G., 1963. Pamiatniki prokhorovskoy kul'tury [Monuments of the Prokhorovka Culture]. Svod Arkheologicheskikh Istochnikov, Д1-10. Moscow, AS USSR. 56 p., 32 tab.

Moshkova M.G., 1974. Proiskhozhdenie rannesarmatskoy (prohorovskoy) kul 'tury [Origin of the Early Sarmatian (Prokhorovka) Culture]. Moscow, Nauka Publ. 51 p.

Nikolaev S.Yu., 2019. Kompleks sarmatskogo klinkovogo oruzhiya iz okrestnostey sel Kuezbashevo i Bishkain v Yuzhnom Priural'e [A Complex of Sarmatian Bladed Weapons from the Vicinity of the Villages of Kuezbashevo and Bishkain in the Southern Cis-Urals]. Ufimskiy arkheologicheskiy vestnik [The Ufa Archaeological Herald], iss. 19, pp. 69-77. DOI: https://doi.org/10.31833/uav.2019.19.006.

Nikolaev S.Yu., 2021a. Mechi i kinzhaly s kol'tsevidnym navershiem: sluchaynye nahodki s territorii Yuzhnogo Priural'ya [Swords and Daggers with Ring Pommels: Accidental Finds from the Territory of the Southern Cis-Urals]. Arheologiya evraziyskih stepey [Archaeology of the Eurasian Steppes], no. 2, pp. 170-174. DOI: https://doi.org/ 10.24852/2587-6112.2021.2.170.174.

Nikolaev S.Yu., 2021b. Sluchaynye nahodki mechey i kinzhalov rannih kochevnikov severo-vostochnoy periferii stepey Yuzhnogo Priural'ya (vtoraya polovina I tys. do n.e. - rubezh er) [Random Finds of Swords and Daggers of Early Nomads of the North-Eastern Periphery of the Steppes of the Southern Urals III BC-the Turn of the Era]. Ufimskiy arkheologicheskiy vestnik [The Ufa Archaeological Herald], 2021, vol. 21, no. 1, pp. 128-144. DOI: https://doi.org/10.31833/uav/2021.21.1.012.

Pshenichnyuk A.H., 1983. Kul'tura rannih kochevnikov Yuzhnogo Urala [Culture of the Early Nomads of the South Urals]. Moscow, Nauka Publ. 199 p.

Savelev N.S., 2016. Mechi i kinzhaly v kul'tovoy praktike kochevnikov Yuzhnogo Priural'ya skifo-sarmatskogo vremeni (prostranstvennyy analiz «sluchaynyh» nahodok) [Swords and Daggers in Religious Practices of Southern Urals Nomads from Skythian-Sarmatian Time (Spatial Analysis of 'Accidental Finds')]. Konstantin Fedorovich Smirnov i sovremennye problemy sarmatskoy arkheologii: materialy IX Mezhdunarodnoy nauchnoy konferentsii «Problemy sarmatskoy arkheologii i istorii» [Konstantin Fedorovich Smirnov and Modern Problems of Sarmatian Archaeology. Proceedings of the IX International Scientific Conference "Problems of Sarmatian Archaeology and History"]. Orenburg, OSPU, pp. 241-253.

Savelev N.S., 2018. Nahodki mechey i kinzhalov skifo-sarmatskogo vremeni iz yugo-zapadnyh predgoriy Yuzhnogo Urala (k voprosu ob osvoenii territorii i osobennostyah rasseleniya kochevnikov) [Swords and Daggers of the Scytho-Sarmatian Period: Finds from Southwestern Foothills of the Southern Ural (Development of the Territory and Dispersal of the Nomadic Population Revisited)]. Oriental Studies, vol. 11, no. 4, pp. 24-31.

Savelev N.S., Nikolaev S.Yu., 2020. Kompleks sarmatskih kinzhalov iz okrestnostej s. Tolbazy v Yuzhnom Priural'e [Sarmatian Dagger Complex from the Surrounding Area the Village Tolbazy in the Southern Urals]. Nizhnevolzhskiy arheologicheskiy vestnik [The Lower Volga Archaeological Bulletin], vol. 19, no. 1, pp. 149166. DOI: https://doi.org/10.15688/nav.jvolsu.2020.1.8.

Sadykova M.H., 1962a. Sarmatskij kurgannyj mogil'nik u der. Starye Kiishki [Sarmatian barrow burial ground near Starye Kiishki village]. Arheologiya i etnografiya Bashkirii [Archeology and ethnography of Bashkiria], vol. 1. Ufa, BFAS USSR, pp. 88-122.

Sadykova M.H., 1962b. Sarmatskie pamyatniki Bashkirii [Sarmatian archaeological monuments of Bashkiria]. Materialy i issledovaniya po arkheologii SSSR [Materials and Research on Archaeology of the USSR], iss. 115. Moscow, AS USSR, pp. 242-273.

Sadykova M.H., Vasilev V.N., 2001. Pozdnie prohorovcy v Central'noj Bashkirii [Representatives of the Late Prokhorovka culture in Central Bashkiria]. Ufimskiy arkheologicheskiy vestnik [The Ufa Archaeological Herald], iss. 3, pp. 55-80. 
Skripkin A.S., 2017. Sarmaty [The Sarmatians]. Volgograd, VolSU. 293 p.

Fedorov V.K., 2008. O datirovke 1-4 Prohorovskih kurganov [On the Dating of 1-4 Prokhorov mounds]. Ufimskiy arkheologicheskiy vestnik [The Ufa Archaeological Herald], iss. 8, pp. 69-90.

Fedorov V.K., 2011. Kurgan 12 mogil'nika Starye Kiishki [Barrow 12 of the burial ground Old Kiishki]. Ufimskiy arkheologicheskiy vestnik [The Ufa Archaeological Herald], iss. 11, pp. 28-38.

Yablonskiy L.T., 2010. Prohorovka. U istokov sarmatskoy arkheologii [Prokhorovka. At the Origins of Sarmatian Archaeology]. Moscow, Taus Publ. 384 p.

\section{Information About the Author}

Sergey Yu. Nikolaev, Junior Researcher, Department of Archaeological Research, Ufa Federal Research Center of the Russian Academy of Sciences, Prosp. Oktyabrya, 71, 450054 Ufa, Russian Federation, nikolaev.sergey123@yandex.ru, https://orcid.org/0000-0003-3350-9148

\section{Информация об авторе}

Сергей Юрьевич Николаев, младший научный сотрудник отдела археологических исследований, Уфимский федеральный исследовательский центр РАН, просп. Октября, 71, 450054 г. Уфа, Российская Федерация, nikolaev.sergey123@yandex.ru, https://orcid.org/0000-0003-3350-9148 